\section{(D) Check for updates}

Cite this: Dalton Trans., 2021, 50 13337

Received 28th May 2021

Accepted 20th August 2021

DOI: 10.1039/d1dt01751a

rsc.li/dalton

\title{
Mechanochemical synthesis of mononuclear gold(I) halide complexes of diphosphine ligands with tuneable luminescent properties $\uparrow$
}

\author{
Andrea Deák, (DD *a Csaba Jobbágy, ${ }^{a}$ Attila Demeter, ${ }^{\mathrm{b}}$ Ladislav Čelko, ${ }^{\mathrm{C}}$ \\ Jaroslav Cihlár̆, ${ }^{c}$ Pál T. Szabó, (DD d Péter Ábrányi-Balogh, (D) e Deborah E. Crawford, ${ }^{f}$ \\ David Virieux (D) 9 and Evelina Colacino (iD *g
}

\begin{abstract}
A mechanochemical method is reported for the synthesis of Au(diphos)X complexes of diphosphine (diphos = XantPhos and $\mathrm{N}$-XantPhos) ligands and halide ions $(\mathrm{X}=\mathrm{Cl}$ and I). The $\mathrm{Au}(\mathrm{XantPhos}) \mathrm{X}(\mathbf{1}: \mathrm{X}=\mathrm{Cl}$; 2: $X=1)$ and $\mathrm{Au}(\mathrm{N}$-XantPhos) $\mathrm{Cl}(\mathbf{3})$ complexes exhibited either yellowish green (1) or bluish green (2) emission, whereas $\mathbf{3}$ was seemingly non-emissive in the solid state at room temperature. Blue- (2B) and bluish green (2G) luminescent concomitant solvates of $\mathbf{2}$ were obtained by recrystallization. Luminescent colour changes from blue (2B) or bluish green (2G) to yellow were observed when these forms were subjected to mechanical stimulus, while the original emission colour can be recovered in the presence of solvent vapours. Moreover, the luminescence of $\mathbf{2 B}$ can be reversibly altered between blue and yellow by heating/cooling-cycles. These results demonstrate the power of mechanochemistry in the rapid ( $4 \mathrm{~min}$ reaction time), efficient (up to $98 \%$ yield) and greener synthesis of luminescent and stimuli-responsive gold(I) complexes.
\end{abstract}

\section{Introduction}

Molecular functional materials based on gold(I) complexes have gained increasing attention for their numerous promising applications in new optoelectronic devices, ${ }^{1-3}$ sensing, ${ }^{4,5}$

${ }^{a}$ Supramolecular Chemistry Research Group, Institute of Materials and Environmental Chemistry, Research Centre for Natural Sciences, Eötvös Loránd Research Network (ELKH), Magyar Tudósok körútja 2, 1117 Budapest, Hungary. E-mail: deak.andrea@ttk.hu

${ }^{b}$ Renewable Energy Research Group, Institute of Materials and Environmental Chemistry, Research Centre for Natural Sciences, Eötvös Loránd Research Network (ELKH), Magyar Tudósok körútja 2, 1117 Budapest, Hungary

${ }^{c}$ Central European Institute of Technology, Brno University of Technology, Purkyňova 123, 61200 Brno, Czech Republic

${ }^{d}$ Centre for Structure Study, Research Centre for Natural Sciences, Eötvös Loránd Research Network (ELKH), 1117 Budapest, Magyar Tudósok körútja 2, Hungary ${ }^{e}$ Medicinal Chemistry Research Group, Institute of Organic Chemistry, Research Centre for Natural Sciences, Eötvös Loránd Research Network (ELKH), 1117 Budapest, Magyar Tudósok körútja 2, Hungary

${ }^{f}$ School of Chemistry and Biosciences, University of Bradford Richmond Road, BD7 $1 D P$ Bradford, UK

${ }^{g}$ ICGM, Univ Montpellier CNRS, ENSCM, Montpellier, France.

E-mail: evelina.colacino@umontpellier.fr

$\dagger$ Electronic supplementary information (ESI) available: Detailed experimental section, HR-MS, ${ }^{1} \mathrm{H}$ and ${ }^{31} \mathrm{P}$ NMR spectra, PXRD patterns, solid state photophysical data, STA analysis. Crystal data, details of data collections and refinements. CCDC 2074756 (2B) and 2074757 (2G). For ESI and crystallographic data in CIF or other electronic format see DOI: 10.1039/d1dt01751a anticancer therapeutics, ${ }^{6}$ bioimaging, ${ }^{7}$ catalysis,${ }^{8}$ gold nanoparticles and nanocluster synthesis. ${ }^{9}$ The gold(I) diphosphine family ${ }^{10}$ is one of the most attractive classes of gold(I) compounds as they exhibit various possible coordination modes, ${ }^{11-17}$ distinct luminescence, ${ }^{11-14,18}$ are stimuli-responsive photophysically, ${ }^{14,18-20}$ catalytic $^{15,16}$ and have promising anticancer properties. ${ }^{21}$ Moreover, mono- and dinuclear gold(I) phosphines have also been used in the preparation of electroluminescent (LED) devices ${ }^{22-24}$ for biochemical ${ }^{25}$ and biomedical applications ${ }^{26,27}$ and for bioimaging. ${ }^{28}$

Indeed, the increasing demand for clean processes and ecoconscious reaction conditions has fostered the application of mechanochemistry in organic ${ }^{29,30}$ and organometallic syntheses, ${ }^{31}$ in metal catalysis, ${ }^{32}$ for the preparation of co-crystals, ${ }^{33}$ metal clusters, ${ }^{34-36}$ metal-organic frameworks $(\mathrm{MOFs})^{37}$ and coordination polymers $(\mathrm{CPs}),{ }^{38,39}$ pharmaceutical materials $\mathrm{s}^{40-42}$ and ingredients (APIs and metallo-drugs). ${ }^{43-45}$ In the last few decades, this technology has provided access to an impressive number of discrete metal complexes, ${ }^{31,46,47}$ as well as infinite $\mathrm{CPs}^{48,49}$ and $\mathrm{MOFs},{ }^{49}$ in a rapid and environmentally-sustainable fashion. Furthermore, it should be noted that there is the possibility to translate mechanochemical batch protocols at laboratory scale into continuous manufacturing, large-scale processes by twin screw extrusion (TSE), ${ }^{50}$ not only for the preparation of APIs, ${ }^{51}$ but also to access OLED materials. ${ }^{52}$ Indeed, very recently, the International Union of 
Pure and Applied Chemistry (IUPAC) has acknowledged TSE as one of the 'top ten emerging technologies in chemistry'. ${ }^{53}$ While there are extensive studies on the conventional solution-based synthesis of gold(I) complexes, ${ }^{54,55}$ the use of mechanochemical methods remains limited despite their unique properties. Friščić et al. reported the mechanochemical oxidation of gold into simple water-soluble $\mathrm{KAuCl}_{4}$ and $\mathrm{NH}_{4} \mathrm{AuCl}_{4}$ salts, followed by reduction with $\mathrm{Ph}_{3} \mathrm{P}$ into the monomeric $\left(\mathrm{Ph}_{3} \mathrm{P}\right) \mathrm{AuCl}$ complex. ${ }^{56}$ Pilarski et al. demonstrated the usefulness of mechanochemistry in the synthesis of (hetero)arylAu(I) complexes. ${ }^{57}$ We demonstrated the effectiveness of mechanochemistry in the synthesis of dinuclear $\left[\mathrm{Au}_{2}(\text { diphos })_{2}\right](\mathrm{X})_{2}$ complexes of diverse diphosphine (diphos) ligands, which exhibit unique luminescent properties. ${ }^{13,18}$ Moreover, we also prepared, by mechanochemical anion-exchange, a set of stimuli-responsive luminescent crystalline and amorphous $\left[\mathrm{Au}_{2}(\operatorname{diphos})_{2}\right](\mathrm{X})_{2}$ complexes. ${ }^{58}$ The striking stimuli-responsive luminescence of these gold(I) compounds has been correlated with external stimuli induced changes in the intra- and/or intermolecular noncovalent interactions such as aurophilic, hydrogen bonding and $\pi \cdots \pi$ stacking. ${ }^{19,20}$ Although, the usefulness of mechanochemistry for the generation of the above mentioned materials has been demonstrated, the mechanochemical synthesis of mononuclear gold(I) halide complexes of diphosphine ligands, Au(diphos)X, has never been reported.

Encouraged by these results, and the growing need for a rapid, simple and efficient approach to high value products or functional metal complexes, we were interested in using mechanochemical methods as a versatile tool to build a more sustainable, rapid and simple approach for the preparation of $\mathrm{Au}($ diphos)X complexes. Three-coordinate gold(I) complexes of diphos ligands and halide ions are rare, and only the solutionbased preparation of $\mathrm{Au}$ (Xantphos)X (XantPhos = 9,9-dimethyl4,5-bis(diphenylphosphino)-xanthene; $\mathrm{X}=\mathrm{Cl}^{15,16}$ and $\mathrm{I}{ }^{59}$ complexes 1 and 2 respectively in Scheme 1), Au(Rphos)Cl (Rphos = 1,2-bis[bis(2-methylphenyl)phosphino]benzene or 1,2-bis[bis(2ethylphenyl)phosphino]benzene) $)^{12}$ and solvothermal synthesis of $\mathrm{Au}(N$-XantPhos)I ( $N$-XantPhos $=4$,6-bis(diphenylphosphino)phenoxazine $)^{59}$ have been reported so far. The solvent-based synthesis of these Xantphos- and $\mathrm{N}$-XantPhos-derived gold(I) compounds required longer reaction times (up to 120 minutes), ${ }^{15,16,59}$ whereas

a)

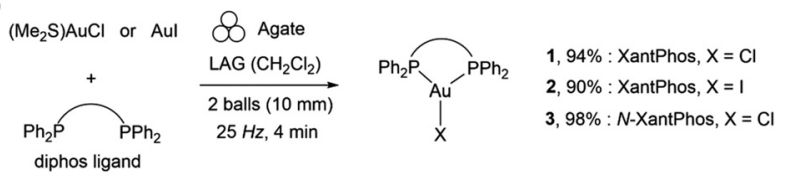

b)

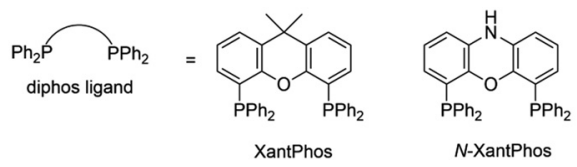

Scheme 1 (a) Mononuclear three-coordinate 1-3 complexes prepared by mechanochemistry; (b) ligands. Mechanochemical activation was represented with the formalism recently introduced. ${ }^{47}$ the use of ball-milling conditions could provide a general environmentally friendly approach to obtain gold(I) complexes with dramatically reduced solvent use, reaction times and improved yields, compared to solution-based procedures.

As an extension of our studies on mechanochemical synthesis of dinuclear gold(I) complexes, we now employ minimalsolvent conditions and dramatically reduced reaction times for the mechanochemical synthesis of $\mathrm{Au}($ diphos)X complexes. Moreover, these three-coordinate gold(I) complexes are expected to luminesce, thus, systematic variation in the nature of diphosphines and halide ions is also expected to result in an efficient tuning of the solid state luminescence and stimuliresponsive properties of these complexes. ${ }^{19,20,26}$ Moreover, due the unique properties of gold(I) complexes and their applications for biomedical purposes, ${ }^{25-27}$ their preparation by mechanochemistry will contribute to a flourishing area of investigation referred to as 'medicinal mechanochemistry'. ${ }^{41}$ Indeed, gold(I) complexes have been FDA approved as oral drug for the treatment of rheumatoid arthritis, selectively targetting cysteine sites in glutathione, proteins and enzymes upon rapid ligand displacement in vivo. ${ }^{25}$

\section{Results and discussion}

Mononuclear, three-coordinate $\mathrm{Au}($ diphos)X (1-3) complexes of chelating bidentate diphosphine ligands (Scheme 1) were synthesised mechanochemically (see ESI, Table S1†).

In all cases, ball milling stoichiometric amounts of the gold(I) precursors, $\left(\mathrm{Me}_{2} \mathrm{~S}\right) \mathrm{AuCl}$ or AuI, with the corresponding diphosphine ligands in a 1:1 stoichiometric ratio under liquid-assisted grinding conditions (LAG; liquid-to-reactant ratio $\left.\eta=0.25 \mu \mathrm{L} \mathrm{mg}^{-1}\right)^{60}$ gave the expected mononuclear complexes 1-3, as determined by HRMS and other analytical techniques (Scheme 1 and ESI $\dagger$ ).

As shown in Fig. 1, product formation is also easily observed by the appearance of a luminescence colour of the barely emitting reaction mixture, as complexes $\mathbf{1}$ and 2 exposed to $365 \mathrm{~nm}$ UV light illumination emit intense yellowish green and bluish green light. Complex $\mathbf{3}$, however, is nonemissive upon exposure to $365 \mathrm{~nm}$ UV light illumination.

Even though the yields obtained from the solution synthesis (87\% for both complexes 1 and 2 and 98\% for complex 3) were comparable with those obtained by mechanochemistry (94\%, 90\% and 98\% respectively for complexes 1-3, see ESI, Table $\mathrm{S} 1 \dagger$ ) the reaction time (4 minutes) needed for the mechanochemical synthesis of complexes 1-3 was significantly

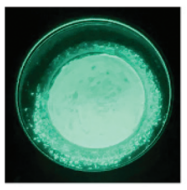

1

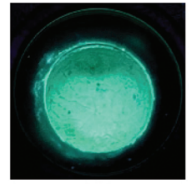

2

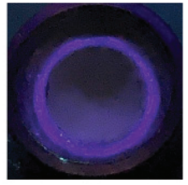

3
Fig. 1 As-prepared 1-3 complexes under 365 nm UV light exposure. 
shorter compared to previously reported solution-based procedures (60 and 30 minutes). ${ }^{15,59}$ Moreover, these reactions proceed in the presence of 105-115 $\mu \mathrm{L}$ quantities of solvent (LAG), compared to $15 \mathrm{~mL}$ quantities of dichloromethane in the conventional synthesis, representing a greener (and less toxic) route to the synthesis of gold(I)-based materials. Additionally, for complexes 1-3 prepared mechanochemically, the work-up was simplified and the products can be recovered as crystalline compounds directly from the ball mill, as indicated by the PXRD patterns (Fig. S11 $\dagger$ ).

The products of LAG reactions were characterized by high resolution mass spectrometry (HRMS), ${ }^{1} \mathrm{H}$ and ${ }^{31} \mathrm{P}$ nuclear magnetic resonance (NMR) spectroscopy, powder (PXRD) and single-crystal X-ray diffraction (2), thermogravimetric analysis coupled with mass spectroscopy (TGA/MS) and fluorescence spectroscopy (see ESI $\dagger$ ). Formation of the mononuclear threecoordinate 1-3 complexes was confirmed by HR-MS analyses of the mechanochemically prepared crude products. The HR-MS spectra of the crude products 1-3 (see ESI, Fig. S1, S3 and $\mathrm{S} 5 \dagger$ ) show the peaks of the corresponding dehalogenated cationic fragments $[\mathrm{Au}(\mathrm{XantPhos})]^{+}$and $[\mathrm{Au}(\mathrm{N} \text {-XantPhos })]^{+}$. The ${ }^{31} \mathrm{P}$ NMR spectra of $\mathbf{1}$ and 2 also display the characteristic singlet resonances of $\mathrm{Au}($ diphos)X species at 28.1 and 26.0 ppm, respectively. However, as it was previously reported by Ito and co-workers, ${ }^{15,16}$ partial disproportionation of $\mathrm{Au}\left(\right.$ XantPhos)Cl (1) to $\mathrm{Au}_{2}$ (XantPhos) $\mathrm{Cl}_{2}$ and $\left[\mathrm{Au}(\mathrm{XantPhos})_{2}\right] \mathrm{Cl}$ occurred immediately after dissolution in $\mathrm{CH}_{2} \mathrm{Cl}_{2}$. The poor solubility of 3 in common organic deuterated solvents hampered its characterisation by solution-based NMR spectroscopy, as previously reported for similar gold(I) complexes. ${ }^{59}$

Solid state photophysical properties of 1-3 complexes were evaluated by measuring their emission and excitation spectra as well as their respective fluorescence lifetimes. Upon excitation at $355 \mathrm{~nm}$, the emission maximum of $\mathbf{1}$ and 2 is centred at 520 and $511 \mathrm{~nm}$ (Fig. S16†), respectively, while 3 is practically nonemissive at room temperature. The emission quantum yields $\left(\Phi_{\text {em }}\right)$ are $0.81(\mathbf{1})$ and $0.33(2)$, respectively. The quantum yield of 2 is comparable to that prepared by solution-based method $\left(\Phi_{\mathrm{em}}=0.28\right) .{ }^{59}$ Both luminescent compounds display biexponential emission decay with two lifetimes of $19.7 \pm 0.3(85 \%)$ and $3.8 \pm 0.2 \mu \mathrm{s}(15 \%)$ for 1 , as well as, $7.0 \pm 0.9(76 \%)$ and $1.66 \pm 0.04 \mu \mathrm{s}(24 \%)$ for 2 . These results demonstrate that the luminescence properties of $\mathrm{Au}($ diphos)X complexes 1 and 2 can be tuned by changing the nature of the halide ions.

Moreover, as shown in Fig. 2, crystallization of 2 by slow evaporation from dichloromethane solution layered with $n$-hexane or $n$-heptane provided blue (2B) and bluish green (2G) luminescent crystals concomitantly. The crystals were separated manually and both were characterized by single crystal X-ray diffraction. This analysis reveals that the 2B and 2G crystals are both dichloromethane solvates of 2 (see ESI, Table S2 $\dagger$ ). The experimental PXRD patterns of mechanochemically prepared bluish green-emitting 2 resemble with the simulated patterns derived from the single crystal data of $\mathbf{2 G}$ form (see ESI, Fig. S17†), however there are additional reflections present only in the diffractogram of 2 .

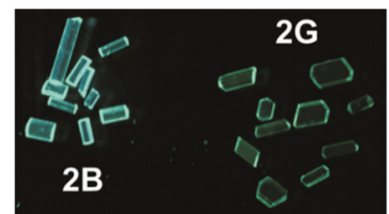

Fig. 2 Optical micrographs showing the sorted concomitant solvates of blue 2B and bluish green 2G luminescent crystals under $365 \mathrm{~nm}$ UVlight exposure.

Polymorph and solvate formation of gold(I) compounds frequently resulted in marked changes in the optical properties, such as luminescence. ${ }^{61-67}$ Three-coordinate gold(I) complexes that lack aurophilic interactions such as $\left(\mathrm{Ph}_{3} \mathrm{P}\right)_{2} \mathrm{AuX}(\mathrm{X}=$ halide $)$ often display polymorphism and exhibit luminescence both in the solid and liquid states. ${ }^{61,62}$ Photocrystallographic studies revealed that photoexcitation-induced structural changes of $\left(\mathrm{Ph}_{3} \mathrm{P}\right)_{2} \mathrm{AuCl}$ molecules caused alterations in the molecular arrangement of the green- and blue-emitting crystals. ${ }^{61,62}$

Moreover, dinuclear three-coordinate gold(I) diphosphine halides, $\mathrm{Au}_{2}$ (dppe) ${ }_{2} \mathrm{X}_{2}$ (dppe = bis-(diphenylphosphino)ethane; $\mathrm{X}=\mathrm{Br}, \mathrm{I})$, alter their emission colour from green to orange upon exposure to solvent vapours. ${ }^{66-68}$ This has been attributed to marked flexibility of $\mathrm{Au}_{2}$ (dppe) ${ }_{2} \mathrm{X}_{2}$ molecules and has been associated with the variations in the $\mathrm{Au}-\mathrm{X}$ and intramolecular $\mathrm{Au} \cdots \mathrm{Au}$ distances, as well as in the $\mathrm{P}-\mathrm{Au}-\mathrm{P}$ angles. ${ }^{66,67}$ Therefore, the polymorphism-dependent emission of 2 allowed us to explore the correlation between the molecular structures or arrangements and photoluminescent behaviour. As shown in Fig. 3, the molecular structure of 2B and $2 \mathbf{G}$ reveals a three-coordinate gold(I) centre with a chelating XantPhos (P-Au-P angle of 116.64(6) ${ }^{\circ}$ in $2 \mathrm{~B}$ and $116.11(4)^{\circ}$ in $\mathbf{2 G}$ ) and coordinated iodide ligand ( $\mathrm{Au}-\mathrm{I}$ bond distance of 2.6883(4) $\AA$ in 2B and 2.7004(3) $\AA$ in 2G). In contrast to centrosymmetric 2B structure with equivalent $\mathrm{Au}-\mathrm{P}$ distance of 2.3403(10) $\AA$, the acentric 2G structure features two Au-P distances of $2.3355(12)$ and $2.3678(11) \AA$, respectively. The most notable conformational difference between these structures (see Fig. 3a) is in the $\mathrm{I}-\mathrm{Au}-\mathrm{P}-\mathrm{C}_{\mathrm{Ph}}$ torsion angles $\left(\theta_{1}=-1.14^{\circ}\right.$, $\theta_{2}=1.14^{\circ}, \theta_{3}=-110.87^{\circ}$ and $\theta_{4}=110.87^{\circ}$ in $2 \mathbf{B} ; \theta_{1}=-12.91^{\circ}$, $\theta_{2}=10.56^{\circ}, \theta_{3}=-136.54^{\circ}$ and $\theta_{4}=133.74^{\circ}$ in 2G). Additionally, the structural analysis also indicates the distortion of the XantPhos ligand backbone in 2G polymorph ( $\mathrm{P}-\mathrm{C}-$ $\mathrm{C}-\mathrm{P}$ torsion angle $\left(\theta_{3}\right)$ is $-2.90^{\circ}$ versus $0.0^{\circ}$ in $\left.2 \mathbf{B}\right)$. Moreover, the conformational flexibility is closely related to the molecular arrangements (Fig. $3 \mathrm{c}$ and d): the columnar stacks of $\mathbf{2 B}$ molecules are linearly arranged (I-Au $\cdots \mathrm{I}-\mathrm{Au}$ torsion angle is $\pm 180.0^{\circ}$ ), while the $2 \mathrm{G}$ molecules show a bent arrangement (I-Au $\cdots \mathrm{I}-\mathrm{Au}$ torsion angle is $158.3^{\circ}$ and $-90.5^{\circ}$ ) along the $c$-axis. There are no intermolecular aurophilic bonds in the crystal structure of these polymorphs, as the shortest distance between the $\mathrm{Au}$ atoms is $8.658 \AA$ (2B) and $10.008 \AA$ (2G), respectively. The disordered dichloromethane molecule forms $\mathrm{C}-\mathrm{H} \cdots \mathrm{Cl}$ interactions $(\mathrm{H} \cdots \mathrm{Cl}$ distance of $2.020(11)$ and

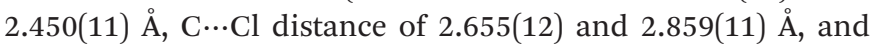



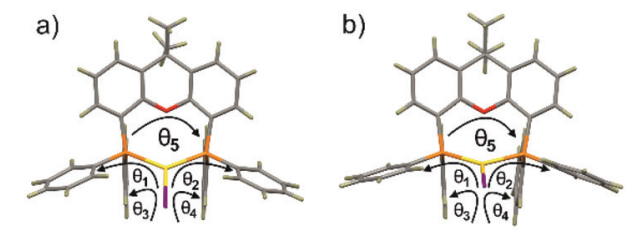

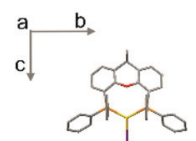<smiles>OCC1CC2CCC1(O)C2(O)O</smiles><smiles>O=C1OC2CCC1C21OCCO1</smiles>
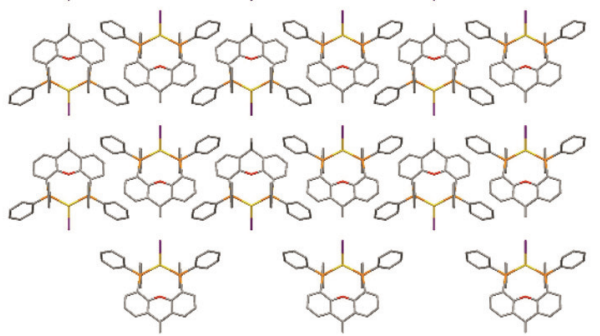

a

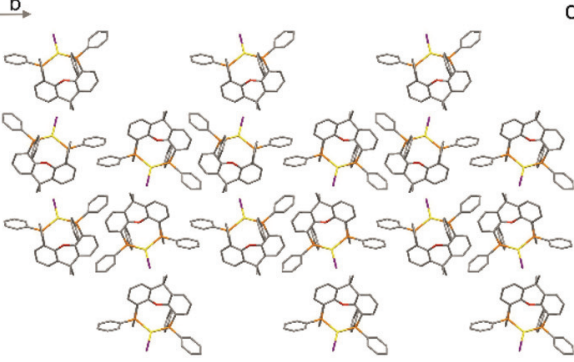

d)

Fig. 3 Molecular structure and molecular arrangement (viewed along the $a$-axis) of blue 2B ( $a$ and $\mathrm{c}$ ) and bluish green luminescent $2 \mathrm{G}$ (b and d) polymorphs, respectively. Disordered parts of $2 \mathrm{~B}$ are not shown, the hydrogen atoms and the dichloromethane molecules are omitted for the clarity in the molecular packing diagrams. Colour scheme: gold, yellow; phosphorous, orange; carbon, grey; oxygen, red; iodide, violet; hydrogen, dark brown.

$\mathrm{C}-\mathrm{H} \cdots \mathrm{Cl}$ angle of $122.0^{\circ}$ and $106.0^{\circ}$ ) with the gold(I) complex in $\mathbf{2 B}$, while there are no hydrogen bonding interactions in $\mathbf{2 G}$. Thus, these polymorphs mainly differ in the orientation of the monomers with respect to one another, and in the nature of the $\mathrm{C}-\mathrm{H} \cdots \mathrm{Cl}$ interactions between the three-coordinated complexes and solvent molecules. In each polymorph, the molecular structure is remarkably similar to that found in the acetonitrile solvate of $2,{ }^{59}$ wherein the molecular complex exhibit a somewhat distorted conformation $\left(\theta_{1}, \theta_{2}\right.$ and $\theta_{3}$ torsion angles of $-14.06,10.29$ and $-4.62^{\circ}$, respectively), which is also reflected in the bent arrangement of the molecules ( $\mathrm{I}-\mathrm{Au} \cdots \mathrm{I}-\mathrm{Au}$ torsion angle is $108.8^{\circ}$ and $-165.3^{\circ}$ ) along the $c$-axis. As shown in Fig. 4ii, the crystals of $\mathbf{2 B}$ and $2 \mathbf{G}$ emit with $\lambda_{\max }=489 \mathrm{~nm}$ (blue) and $502 \mathrm{~nm}$ (bluish green) at room temperature (see ESI, Table S3 $\uparrow$ ), respectively. The emission lifetimes for $\mathbf{2 B}$ and $2 \mathbf{G}$ crystals (see ESI, Table $\mathrm{S} 3 \dagger$ ) are indicative of the phosphorescent character of the emission. The photoemission characteristics of $\mathbf{2 B}$ and $\mathbf{2 G}$ polymorphs, however, are in good agreement with that of acetonitrile solvate of $2\left(\lambda_{\max }=\right.$ $\left.486 \mathrm{~nm} ; \tau_{\mathrm{av}}=9.1 \mu \mathrm{s}\right)^{59}$ prepared by solution-based procedures.
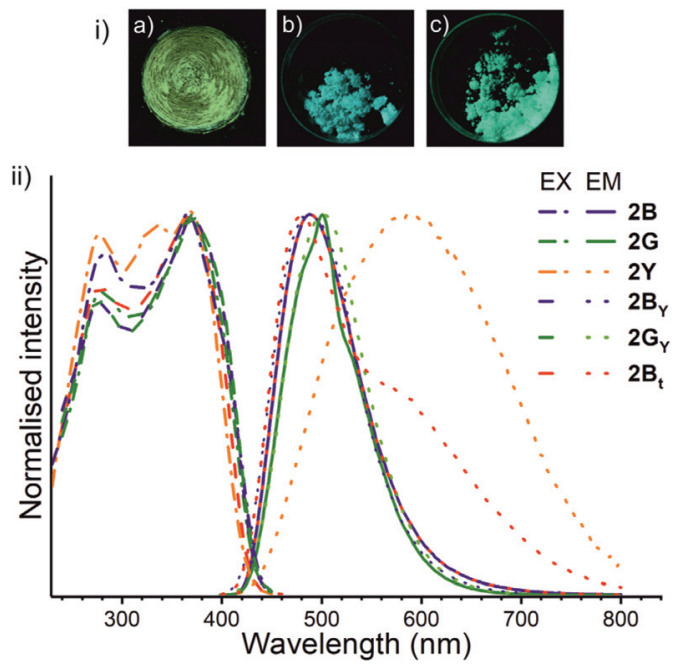

Fig. 4 (i) Photographs showing the (a) amorphous $2 Y$ phase (obtained by ball-milling of $\mathbf{2 B}$ or $\mathbf{2 G}$ ) and (b) crystalline $2 \mathrm{~B}_{\mathrm{Y}}$ and (c) $2 \mathrm{G}_{\mathrm{Y}}$ phases (obtained upon solvent vapour exposure of $2 Y$ ) under $365 \mathrm{~nm}$ UV light illumination; (ii) Normalised excitation and emission spectra of crystalline and amorphous forms of 2 .

It was observed that a number of gold(I) compounds not only exhibited polymorphism-dependent luminescence properties but also displayed changes in the luminescence in response to diverse external-stimuli. ${ }^{19,63-67}$ Thus, the existence of these crystalline phases with distinct multicolour luminescence foreseeds the stimuli-responsive luminescent behaviour of $\mathbf{2}$. Both crystalline phases $\mathbf{2 B}$ and $\mathbf{2 G}$ exhibit mechanochromic luminescence upon milling and give a yellow-emitting $\mathbf{2 Y}$ phase (Fig. 4i) as a consequence of a crystalline-to-amorphous (CTA) phase transformation (see ESI, Fig. S18 and S19†). This amorphous $2 Y$ phase exhibits a broad emission spectrum (Fig. 4ii) with $\lambda_{\max }$ at $588 \mathrm{~nm}$ (see ESI, Table S3†). Exposure of $2 Y$ to dichloromethane vapours afforded a bluish green luminescent $\mathbf{2 G}_{\mathbf{Y}}$ phase, while a blue luminescent $\mathbf{2 B}_{\mathbf{Y}}$ phase was formed in the presence of ethanol vapours (Fig. 4i and ESI, Table S3 $\dagger$ ). As indicated by the PXRD data (see ESI, Fig. S19†), the solvent vapours induce the amorphous-to-crystalline (ATC) phase transition and this leads to vapoluminescent responses. The emission maxima of these $\mathbf{2} \mathbf{G}_{\mathbf{Y}}$ and $\mathbf{2} \mathbf{B}_{\mathbf{Y}}$ phases is at $\mathbf{5 0 1 . 5}$ and $487 \mathrm{~nm}$, respectively (Fig. 4ii, Table S3†). These luminescence switchings induced by mechanical and subsequent chemical stimuli occurred as a consequence of dynamic CTA and ATC phase transitions.

Having identified the mechanochromic and vapochromic luminescence of the polymorphs of 2 , we also explored their thermochromic luminescence properties. The bluish green emission of $\mathbf{2 G}$ faded upon thermal treatment, while reversible luminescence alterations of $\mathbf{2 B}$ was observed upon heating/ cooling cycles. As shown in Fig. 5, a yellow emission appeared when $2 \mathbf{B}$ was heated to $300{ }^{\circ} \mathrm{C}$, which reverted back to an intense blue emission upon cooling back to room temperature. A movie taken under $365 \mathrm{~nm}$ UV light illumination shows the reversible switching between blue and yellow emission during 


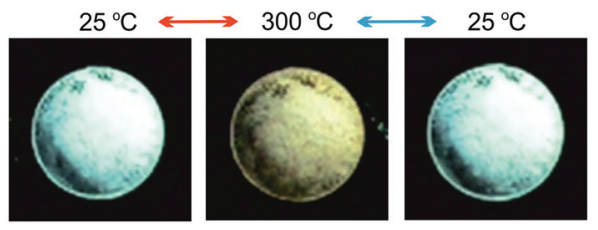

Fig. 5 Reversible thermochromic luminescence of 2B (under $365 \mathrm{~nm}$ UV illumination) upon heating/cooling cycles.

heating and cooling cycles (Movie S1†). Thermogravimetric analysis (TGA), differential scanning calorimetry (DSC), and coupled mass spectrometry (MS) were carried out simultaneously on 2B (see the ESI, Table S4 $\dagger$ ). The results showed that $\mathbf{2 B}$ is thermally stable and no decomposition occurred during heating to $350{ }^{\circ} \mathrm{C}$. The sharp DTG (derivative thermogravimetry) peak was related to the removal of the dichloromethane solvate molecules (Fig. S21 $\dagger$ ). The DSC curve showed that $2 \mathrm{~B}$ melted at $305.9^{\circ} \mathrm{C}$ and this solid-to-liquid phase transformation begins at $289.6{ }^{\circ} \mathrm{C}$ and ends at $315.6{ }^{\circ} \mathrm{C}$ (Fig. S21†). This indicates that at least a part of $2 \mathbf{B}$ converted into an amorphous phase $\left(2 \mathbf{Y}_{\mathbf{t}}\right)$ upon heating to $300{ }^{\circ} \mathrm{C}$ during the thermochromic luminescence experiment, and the observed yellow luminescence originated from the as-resulting amorphous phase. The $\mathbf{2 B}_{\mathbf{t}}$ phase obtained upon cooling back to room temperature also has some amorphous character as evidenced by the presence of broadened peaks in the PXRD patterns (Fig. S19†) and in agreement with the results of the emission spectroscopy data. As shown in Fig. 4ii, there are two wellresolved emission bands with 480 and $600 \mathrm{~nm}$ maxima in the emission spectrum of this new $\mathbf{2 B}_{\mathbf{t}}$ phase (Table $\mathrm{S} 3 \dagger$ ). The blue emitting band (at around $480 \mathrm{~nm}$ ) could be described with an $8 \mathrm{~nm}$ blue shift of the emission spectrum of $2 \mathbf{B}$. However, the other band is much more similar than that of the emission of amorphous $\mathbf{2 Y}$. It is observable on the time-resolved transients that the blue emitting state excites the red emitting one (at least partly), indicating by that there is a quick $(1 \mu \mathrm{s})$ decay in the blue band while in the other transient, a rise of fluorescence intensity may be observed with almost the same time parameter (Fig. S26†). Furthermore, very similar excitation spectra were measured at the 460 and $630 \mathrm{~nm}$ wavelengths (Fig. S26†). Almost all crystalline and amorphous phases of 2 show two or three exponential luminescence decay character (Table S $3 \dagger$ ), which used to be explained by the local disorder in the molecular arrangement due to the presence of residual solvent or multiple molecular conformations in the solid state. ${ }^{69-71}$ Additional experiments aimed to explore the details of this thermally-induced solid state transformation.

\section{Experimental}

All chemicals and solvents used for the syntheses were of reagent grade. The solvents for synthesis were used without further purification. All manipulations were performed in air. Mechanochemical synthesis were performed by a Retsch
MM400 shaker mill in a $10 \mathrm{~mL}$ agate jar with two $10 \mathrm{~mm}$ diameter agate balls (weight of each ball $m=1.5 \mathrm{~g}, m_{\text {tot }}=$ $2 \times 1.5 \mathrm{~g}$ ) operating at $25 \mathrm{~Hz}$.

In a general procedure, stoichiometric amounts of $\left(\mathrm{Me}_{2} \mathrm{~S}\right) \mathrm{AuCl}(147 \mathrm{mg}, 0.50 \mathrm{mmol}$ ) or AuI (162 mg, $0.50 \mathrm{mmol})$ with bidentate phosphine ligands (Table $\mathrm{S} 1 \dagger$ ) were added into a $10 \mathrm{~mL}$ agate milling jar with two $10 \mathrm{~mm}$ diameter agate balls (weight of each ball $m=1.5 \mathrm{~g}, m_{\text {tot }}=2 \times 1.5 \mathrm{~g}$ ). The reaction mixture was then ball milled at $25 \mathrm{~Hz}$ in the presence of few drops (105-115 $\mu \mathrm{L}, \eta=0.25 \mu \mathrm{L} \mathrm{mg}^{-1}$, Table S1†) of dichloromethane for 4 minutes. The crude product of LAG reaction (1-3) can be directly recovered as crystalline material and without any work-up.

High resolution mass spectrometric measurements were performed on a Sciex 5600+ QTof mass spectrometer (Sciex, USA) equipped with DuoSpray ion source operated in electrospray ionization mode. The resolution of the instrument was $>30000$ over the entire mass range. Samples were dissolved in acetonitrile and flow injected into the mass spectrometer. Analyst TF 1.7. software was used for the instrument control and data processing as well. The commonly accepted criteria level of $5 \mathrm{ppm}$ was used during the high-resolution measurements. ${ }^{1} \mathrm{H}$ and ${ }^{31} \mathrm{P}$ NMR spectra were recorded in $\mathrm{CD}_{2} \mathrm{Cl}_{2}$ solution at room temperature, on a Varian Unity Inova 500 spectrometer (500 and $202 \mathrm{MHz}$ for ${ }^{1} \mathrm{H}$ and ${ }^{31} \mathrm{P}$ NMR spectra, respectively), with the residual solvent signal as the lock and TMS as the internal standard. Chemical shifts $(\delta)$ and coupling constants $(J)$ are given in ppm and $\mathrm{Hz}$, respectively. The corrected luminescence spectra were measured with a JASCO FP-8300 spectrofluorometer with $2.5 \mathrm{~nm}$ resolution using $370 \mathrm{~nm}$ light for excitation, the phosphorescence decays with a $25 \mathrm{MHz}$ Hitachi VC-6041 (Z) oscilloscope (with typically $5 \mathrm{~nm}$ resolution) exciting with the third harmonic (355 nm) excitation beam of a Nd-YAG laser (Continuum Surelite) with very low light intensity weakened by neutral filters (less than $0.03 \mathrm{~mJ}$ per flash). The averaged 50-500 flashes were fitted with 1-2-3 exponentials (OriginPro 2018) with background optimization. Furthermore, for $\mathbf{2 G}$ crystals the single exponential decay was checked by a picosecond single photon counting (SPC) equipment (Edinburg Instrument FLSP920 spectrofluorimeter, EPL-378 nm diode laser) producing practically the same result. The absolute emission quantum yields of the solid samples 1 and 2 were determined on a Jobin-Yvon Fluoromax-4 spectrofluorometer equipped with a Ø2" integrating sphere (Thorlabs). The powder X-Ray diffraction analysis of 1-3 (Fig. S19†) was performed on the multifunctional powder diffractometer PANalytical Empyrean using $\mathrm{Cu}$ anode and $\mathrm{K} \alpha$ radiation source, $\lambda=1.540598 \AA$ for $\mathrm{K}_{\alpha 1}$, accelerating voltage $45 \mathrm{kV}$, beam current $40 \mathrm{~mA}$, diffraction angle $2 \theta$ in the range from $5^{\circ}$ to $35^{\circ}$ with a step scan of $0.04^{\circ}$. Collected data were evaluated using the PANalytical X'Pert HighScore Plus software and ICSD 2012, COD 2011 and PDF2 databases. Powder diffractograms (Fig. S11, S12 and $\mathrm{S} 17 \dagger$ ) were produced with $\mathrm{Cu}-\mathrm{K} \alpha$ radiation on a vertical high-angle Philips PW1050 powder diffractometer. Single crystals of $\mathbf{2 B}$ and $\mathbf{2 G}$ were mounted in Paratone-N oil within a conventional cryo-loop, and intensity 
data were collected on a Rigaku R-AXIS RAPID image plate diffractometer $(\lambda($ Mo-K $\alpha$ radiation $)=0.71075 \AA$, fitted with an $\mathrm{X}$-stream low temperature attachment (see the ESI, Table S2 $\dagger$ ). Optical micrographs were recorded with a Linkam Imaging Station microscope equipped with Nikon DS-Fi1c digital camera and $365 \mathrm{~nm}$ hand-held UV lamp. Linkam DSC600 stage has been used to study the reversible thermochromic luminescence of 2B. Thermogravimetric analysis (TGA), differential scanning calorimetry (DSC), and coupled mass spectrometry (MS) were carried out simultaneously (TGA-DSC-MS) in a Netzsch STA 409c/CD apparatus. Analyses were performed in an argon atmosphere using $\mathrm{Al}_{2} \mathrm{O}_{3}$ crucibles. Simultaneous thermal analysis (STA) of the $\mathbf{2 B}$ was performed according to the program: first heating from $25{ }^{\circ} \mathrm{C}$ to $350{ }^{\circ} \mathrm{C}$ at a rate of $5{ }^{\circ} \mathrm{C} \min ^{-1}$, cooling from $350{ }^{\circ} \mathrm{C}$ to $80^{\circ} \mathrm{C}$ at a rate of $10{ }^{\circ} \mathrm{C}$ $\min ^{-1}$ and second heating from $80{ }^{\circ} \mathrm{C}$ to $450{ }^{\circ} \mathrm{C}$ at a rate of $5^{\circ} \mathrm{C} \min ^{-1}$ (Fig. S21†).

\section{Conclusions}

In summary, we have demonstrated the power of mechanochemistry in the simple and rapid synthesis of highly luminescent mononuclear, three-coordinate $\mathrm{Au}($ diphos)X complexes. To the best of our knowledge, this is the first report on the mechanochemical synthesis of gold(I) halide complexes of diphosphines ligands, wherein the systematic variation in the nature of diphosphine ligands and halide ions coupled with the phase change properties allows luminescences colour tuning from blue to green and to yellow. In the case of gold(I) complexes 1 and 2, solution-based procedures and mechanochemical syntheses were comparable in terms of yields. ${ }^{15,59}$ However, mechanochemistry outperformed in comparison to previously reported solution-based procedures ${ }^{15,59}$ as the reaction times were significantly shorter (only four minutes instead of hours), the method is practically solvent-free, the experimental set-up is simple (no need of dry solvents or washing/precipitation operations during the work-up), the reactions proceeding with an overall reduced ecological footprint. Scheme 2 summarizes the stimuli-induced transformations among different forms of 2 that we have observed. Thus, it was also possible to discover two different solvates of 2 with distinct blue and bluish green luminescence that also

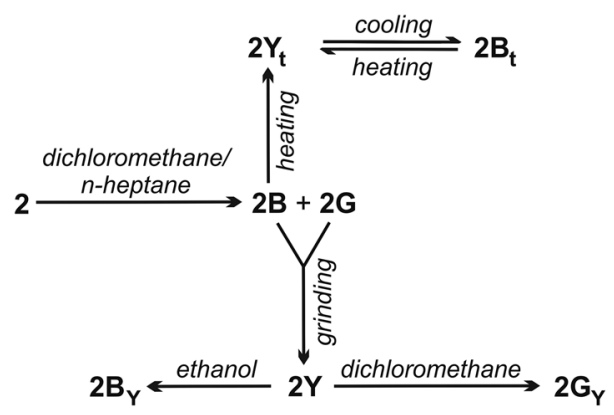

Scheme 2 Stimuli-induced transformations of 2 forms. displayed stimuli-responsive luminescent behaviour. Upon mechanical grinding both polymorphs alter their luminescence into yellow, which converted back into original emission colours in the presence of different solvent vapours. A reversible blue-to-yellow emission change of $\mathbf{2 B}$ was observed during consecutive heating and cooling cycles over a temperature range of $25-300{ }^{\circ} \mathrm{C}$. Such multistimuli-responsive materials, which show luminescent colour changes in response to mechanical grinding, in the presence of volatile chemical compounds or temperature alteration are of great promise owing to their potential applications in sensing-, switching- and optical-recording systems.

\section{Conflicts of interest}

There are no conflicts to declare.

\section{Acknowledgements}

This article is based upon work from COST Action CA18112, ${ }^{72,73}$ supported by COST (European Cooperation in Science and Technology).\$\$ The authors are indebted to Dr Tamás Holczbauer, Dr Nóra May and Laura Nagyné Dr Bereczki for single crystal X-ray diffraction (Research Centre for Natural Sciences, Eötvös Loránd Research Network, Budapest, Hungary) and Mariano Casas Luna (Central European Institute of Technology, Brno University of Technology, Brno, Czech Republic) for the PXRD measurements.

\section{Notes and references}

1 V. W.-W. Yam, V. K.-M. Au and S. Y.-L. Leung, Chem. Rev., 2015, 115, 7589-7728.

2 E. Y. Hong and V. W.-W. Yam, ACS Appl. Mater. Interfaces, 2017, 9, 2616-2624.

3 D. Di, A. S. Romanov, L. Yang, J. M. Richter, J. P. Rivett, S. Jones, T. H. Thomas, M. Abdi Jalebi, R. H. Friend, M. Linnolahti, M. Bochmann and D. Credgington, Science, 2017, 356, 159-163.

4 C. Y. Liu, H. F. Wang, Z. G. Ren, P. Braunstein and J. P. Lang, Inorg. Chem., 2019, 58, 8533-8540.

5 J. X. Chen, W. H. Zhang, X. Y. Tang, Z. G. Ren, H. X. Li, Y. Zhang and J. P. Lang, Inorg. Chem., 2006, 45, 7671-7680.

6 T. Zou, C. T. Lum, C. N. Lok, J. J. Zhang and C. M. Che, Chem. Soc. Rev., 2015, 44, 8786-8801.

7 C. Y. Liu, X. R. Wei, Y. Chen, H. F. Wang, J. F. Ge, Y. J. Xu, Z. G. Ren, P. Braunstein and J. P. Lang, Inorg. Chem., 2019, 58, 3690-3697.

$\ddagger$ For more information on COST Action CA18112 'Mechanochemistry for Sustainable Industry' (MechSustInd): http://www.mechsustind.eu/. $\S$ For more information on COST Association: http://www.cost.eu/. 
8 R. Ciriminna, E. Falletta, C. Della Pina, J. H. Teles and M. Pagliaro, Angew. Chem., Int. Ed., 2016, 55, 14210-14217.

9 R. Jin, Y. Zhu and H. Qian, Chem. - Eur. J., 2011, 17, 65846593.

10 A. V. Paderina, I. O. Koshevoy and E. V. Grachova, Dalton Trans., 2021, 50, 6003-6033.

11 A. Pintado-Alba, H. de la Riva, M. Nieuwhuyzen, D. Bautista, P. R. Raithby, H. A. Sparkes, S. J. Teat, J. M. Lopez-de-Luzuriaga and M. C. Lagunas, Dalton Trans., 2004, 3459-3467.

12 M. Osawa, M. A. Aino, T. Nagakura, M. Hoshino, Y. Tanaka and M. Akita, Dalton Trans., 2018, 47, 8229-8239.

13 C. Jobbágy, P. Baranyai, G. Marsi, B. Rácz, L. Li, P. Naumov and A. Deák, J. Mater. Chem. C, 2016, 4, 10253-10264.

14 P. Baranyai, G. Marsi, C. Jobbágy, A. Domján, L. Oláh and A. Deák, Dalton Trans., 2015, 44, 13455-13459.

15 H. Ito, K. Takagi, T. Miyahara and M. Sawamura, Org. Lett., 2005, 7, 3001-3004.

16 H. Ito, T. Saito, T. Miyahara, C. Zhong and M. Sawamura, Organometallics, 2009, 28, 4829-4840.

17 A. X. Zheng, Z. G. Ren, L. L. Li, H. Shang, H. X. Li and J. P. Lang, Dalton Trans., 2011, 40, 589-596.

18 A. Deák, C. Jobbágy, G. Marsi, M. Molnár, Z. Szakács and P. Baranyai, Chem. - Eur. J., 2015, 21, 11495-11508.

19 A. Deák, in Nanomaterials Design for Sensing Applications, ed. O. V. Zenkina, Elsevier Inc., 2019, ch. 9, pp. 281-324.

20 C. Jobbágy and A. Deák, Eur. J. Inorg. Chem., 2014, 44344449.

21 N. Mirzadeh, T. S. Reddy and S. K. Bhargava, Coord. Chem. Rev., 2019, 388, 343-359.

22 V. W.-W. Yam, C.-L. Chan, S. W.-K. Choi, K. M.-C. Wong, E. C.-C. Cheng, S.-C. Yu, P.-K. Ng, W.-K. Chan and K.-K. Cheung, Chem. Commun., 2000, 53-54.

23 Y. Ma, X. Zhou, J. Shen, H.-Y. Chao and C.-M. Che, Appl. Phys. Lett., 1999, 74, 1361-1363.

24 Y. Ma, C.-M. Che, H.-Y. Chao, X. Zhou, W.-H. Chan and J. Shen, Adv. Mater., 1999, 11, 852-857.

25 H. E. Abdou, A. A. Mohamed, J. P. Fackler, A. Burini, R. Galassi, J. M. López-de-Luzuriaga and M. E. Olmos, Coord. Chem. Rev., 2009, 253, 1661-1669.

26 A. A. Karasik, E. I. Musina, I. D. Strelnik, I. R. Dayanova, J. G. Elistratova, A. R. Mustafina and O. G. Sinyashin, Pure Appl. Chem., 2019, 91, 839-849.

27 B. Dominelli, J. D. G. Correia and F. E. Kühn, J. Organomet. Chem., 2018, 866, 153-164.

28 E. E. Langdon-Jones and S. J. Pope, Chem. Commun., 2014, 50, 10343-10354.

29 S. L. James, C. J. Adams, C. Bolm, D. Braga, P. Collier, T. Friščić, F. Grepioni, K. D. Harris, G. Hyett, W. Jones, A. Krebs, J. Mack, L. Maini, A. G. Orpen, I. P. Parkin, W. C. Shearouse, J. W. Steed and D. C. Waddell, Chem. Soc. Rev., 2012, 41, 413-447.

30 T. Friščić, C. Mottillo and H. M. Titi, Angew. Chem., 2020, 59, 1018-1029.

31 D. Tan and F. Garcia, Chem. Soc. Rev., 2019, 48, 22742292.
32 A. Porcheddu, E. Colacino, L. De Luca and F. Delogu, ACS Catal., 2020, 10, 8344-8394.

33 D. Braga, L. Maini and F. Grepioni, Chem. Soc. Rev., 2013, 42, 7638-7648.

34 J. X. Chen, Q. F. Xu, Y. Xu, Y. Zhang, Z. N. Chen and J. P. Lang, Eur. J. Inorg. Chem., 2004, 2004, 4247-4252.

35 H. Yu, Q. F. Xu, Z. R. Sun, S. J. Ji, J. X. Chen, Q. Liu, J. P. Lang and K. Tatsumi, Chem. Commun., 2001, 26142615.

36 J. P. Lang and K. Tatsumi, Inorg. Chem., 1998, 37, 63086316.

37 A. Lazuen-Garay, A. Pichon and S. L. James, Chem. Soc. Rev., 2007, 36, 846-855.

38 V. Cabras, M. Pilloni, A. Scano, R. Lai, M. C. Aragoni, S. J. Coles and G. Ennas, Eur. J. Inorg. Chem., 2017, 19081914.

39 F. Wang, C. Y. Ni, Q. Liu, F. L. Li, J. Shi, H. X. Li and J. P. Lang, Chem. Commun., 2013, 49, 9248-9250.

40 D. Hasa and W. Jones, Adv. Drug Delivery Rev., 2017, 117, 147-161.

41 D. Tan, L. Loots and T. Friščić, Chem. Commun., 2016, 52, 7760-7781.

42 S. Quaresma, V. André, A. Fernandes and M. T. Duarte, Inorg. Chim. Acta, 2017, 455, 309-318.

43 M. Pérez-Venegas and E. Juaristi, ACS Sustainable Chem. Eng., 2020, 8, 8881-8893.

44 E. Colacino, A. Porcheddu, C. Charnay and F. Delogu, React. Chem. Eng., 2019, 4, 1179-1188.

45 A. S. McCalmont, A. Ruiz, M. C. Lagunas, W. T. Al-Jamal and D. E. Crawford, ACS Sustainable Chem. Eng., 2020, 8, 15243-15249.

46 A. Beillard, X. Bantreil, T. X. Metro, J. Martinez and F. Lamaty, Chem. Rev., 2019, 119, 7529-7609.

47 N. R. Rightmire and T. P. Hanusa, Dalton Trans., 2016, 45, 2352-2362.

48 C. Jobbágy, T. Tunyogi, G. Pálinkas and A. Deák, Inorg. Chem., 2011, 50, 7301-7308.

49 T. Friščić, Chem. Soc. Rev., 2012, 41, 3493-3510.

50 E. Colacino, V. Isoni, D. Crawford and F. Garcia, Trends Chem., 2021, 3, 335-339.

51 D. E. Crawford, A. Porcheddu, A. S. McCalmont, F. Delogu, S. L. James and E. Colacino, ACS Sustainable Chem. Eng., 2020, 8, 12230-12238.

52 D. E. Crawford, S. L. James and T. McNally, ACS Sustainable Chem. Eng., 2017, 6, 193-201.

53 F. Gomollón-Bel, Chem. Int., 2019, 41, 12-17.

54 M. C. Gimeno and A. Laguna, Chem. Rev., 1997, 97, 511522.

55 M. C. Gimeno, in Modern Supramolecular Gold Chemistry, ed. A. Laguna, WILEY-VCH Verlag GmbH \& Co. KGaA, Weinheim, 2008, pp. 1-63.

56 J. L. Do, D. Tan and T. Friščić, Angew. Chem., Int. Ed., 2018, 57, 2667-2671.

57 F. J. L. Ingner, Z. X. Giustra, S. Novosedlik, A. Orthaber, P. J. Gates, C. Dyrager and L. T. Pilarski, Green Chem., 2020, 22, 5648-5655. 
58 C. Jobbágy, M. Molnár, P. Baranyai and A. Deák, Dalton Trans., 2014, 43, 11807-11810.

59 N. Glebko, T. M. Dau, A. S. Melnikov, E. V. Grachova, I. V. Solovyev, A. Belyaev, A. J. Karttunen and I. O. Koshevoy, Chem. - Eur. J., 2018, 24, 3021-3029.

60 T. Friščić, S. L. Childs, S. A. A. Rizvi and W. Jones, CrystEngComm, 2009, 11, 418-426.

61 M. Hoshino, H. Uekusa, S. Sonoda, T. Otsuka and Y. Kaizu, Dalton Trans., 2009, 3085-3091.

62 M. Hoshino, H. Uekusa, S. Ishii, T. Otsuka, Y. Kaizu, Y. Ozawa and K. Toriumi, Inorg. Chem., 2010, 49, 72577265.

63 T. Seki, S. Kurenuma and H. Ito, Chem. - Eur. J., 2013, 19, 16214-16220.

64 T. Seki, T. Ozaki, T. Okura, K. Asakura, A. Sakon, H. Uekusa and H. Ito, Chem. Sci., 2015, 6, 2187-2195.

65 M. A. Malwitz, S. H. Lim, R. L. White-Morris, D. M. Pham, M. M. Olmstead and A. L. Balch, J. Am. Chem. Soc., 2012, 134, 10885-10893.
66 S. H. Lim, M. M. Olmstead and A. L. Balch, J. Am. Chem. Soc., 2011, 133, 10229-10238.

67 S. H. Lim, M. M. Olmstead and A. L. Balch, Chem. Sci., 2013, 4, 311-318.

68 O. S. Wenger, Chem. Rev., 2013, 113, 3686-3733.

69 M. T. Dau, J. R. Shakirova, A. J. Karttunen, E. V. Grachova, S. P. Tunik, A. S. Melnikov, T. A. Pakkanen and I. O. Koshevoy, Inorg. Chem., 2014, 53, 4705-4715.

70 A. Demeter and K. A. Zachariasse, Chem. Phys. Lett., 2003, 380, 699-703.

71 J. R. Lakowicz, Principles of Fluorescence Spectroscopy, Springer, 3rd edn, 2006.

72 M. Baláž, L. Vella-Zarb, J. G. Hernández, I. Halasz, D. E. Crawford, M. Krupička, V. André, A. Niidu, F. García, L. Maini and E. Colacino, Chim. Oggi-Chem. Today, 2019, 37, 32-34.

73 J. G. Hernández, I. Halasz, D. E. Crawford, M. Krupicka, M. Baláž, V. André, L. Vella-Zarb, A. Niidu, F. García, L. Maini and E. Colacino, Eur. J. Org. Chem., 2020, 8-9. 